http://www.jfas.info

\title{
THE CRITERIA FOR EVALUATING METHOD AND EVIDENCE ON RADIATION HEALTH EFFECTS IN EPIDEMIOLOGICAL STUDY: A REVIEW
}

\author{
F. M. Yussof ${ }^{1}$, R. Umar ${ }^{1}$, H. Juahir ${ }^{2}$ and A. Hassan ${ }^{1, *}$ \\ ${ }^{1}$ Insitute Community Development and Quality of Life, Universiti Sultan Zainal Abidin, \\ Gong Badak Campus, 21300 Kuala Nerus, Terengganu, Malaysia \\ ${ }^{2}$ East Coast Environmental Research Institute (ESERI), Universiti Sultan Zainal Abidin, \\ Gong Badak Campus, 21300 Kuala Nerus, Terengganu, Malaysia
}

Published online: 08 August 2017

\begin{abstract}
This paper purpose is to assess whether the distance of base station plays a causal role leading to health problem. This research mostly focuses on participants around telecommunication base stations by assessing their symptoms and level of the incident of occurrence of pains and discomfort. It is important to rule out all the criteria and causality from cause and outcome in radiation health effects through epidemiological study. The major causal criteria to follow are criteria of biological plausibility, consistency, temporality and specificity of alternative explanations. True EMR value also should be determined to support the survey collection. Previous studies mostly have been performed were limited to the questionnaire survey and often burdened by the subjectivism-related error. The evidence for public health intervention must be sufficiently comprehensive to cover the complexity in epidemiological studies.
\end{abstract}

Keywords: base stations; electromagnetic radiation (EMR); health effect; questionnaire.

Author Correspondence, e-mail: azmihassan@unisza.edu.my

doi: http://dx.doi.org/10.4314/jfas.v9i2s.22 


\section{INTRODUCTION}

Public exposures to Electromagnetic radiation (EMR) are not a new fact and are one of the factors that contribute to public concerns. The purpose of this study was to evaluate the best method that has the ability to rate and assessing health symptoms and level of the incident of occurrence of pains and discomfort among respondents that exposed to electromagnetic radiation. Radiation can cause negative biological effects on living things, which may vary depending on the dose and the duration of exposure [1-2]. EMR sources came from the smart meter, mobile phones, wireless network, household $50 \mathrm{~Hz}$ electric and magnetic fields, mobile phone base stations, broadcast towers, cordless phones, distribution power lines and smart meter base station. EMR can be harmful to human body depending upon the radiated power density emitted by EMR and absorbed by human charged particles [3]. Table 1 shows that a wide range of neuropsychiatric effects were produced by exposure to various sources of electromagnetic radiation and methods use in identify health effects in epidemiological studies.

The increasing in extensive used and installation of high-voltage overhead power lines and base station hassled to public concerns and give the increase on a scientific debate regarding EMR potential health effects in the community [4]. EMR emitted by mobile phones has caused the increase of public concern about EMR health effects. A headache, tremors, memory changes, depressive symptoms, dizziness symptoms and sleep disturbance were the symptoms and disease that the inhabitants around mobile base stations have developed during exposing to EMR radiation [5]. Exposure assessment in radiation health effect in epidemiological studies is most often done by self-report [6]. One of the factors that can affect the validity of self-report in epidemiological studies was the imprecision of exposure assessment in the studies that likely to occur in case-control studies [7]. They support the beliefs of some studies that the standards fail to ensure sufficient protection to the general population [8]. However, many of those papers were burden with errors resulting from questionnaire format, selection of study group and insufficiently precise assessment of EMF exposure. Besides, other EMR sources were often neglected [9]. In some of the studies done, the results are not always coherent where health problems arise at a shorter distance from the 
base station [10] while measured EMR intensity did not correlate with the frequency of the complaints [11].

Based on [12], the most complaints in Australian regarding radiation health effects were headaches followed by heart arrhythmia, nausea, poor concentration, anxiety, insomnia, lethargy, dizziness, burning sensation and disturbed sleep [12]. Similar list of common neuropsychiatric symptoms was found in electromagnetic hypersensitivity (EHS) which were poor short term memory, lack of concentration, body pain, sleep disturbance, headache, dizziness, tinnitus, eye problems, chronic fatigue, tremors, difficulty in speaking, tingling sensation in hands or feets, difficulty writing, difficulty walking and migraine [13]. These types of symptom commonly found when people exposed to EMR for a specific duration of time. 


\section{Neurobehavioral Symptoms near Cell Towers}

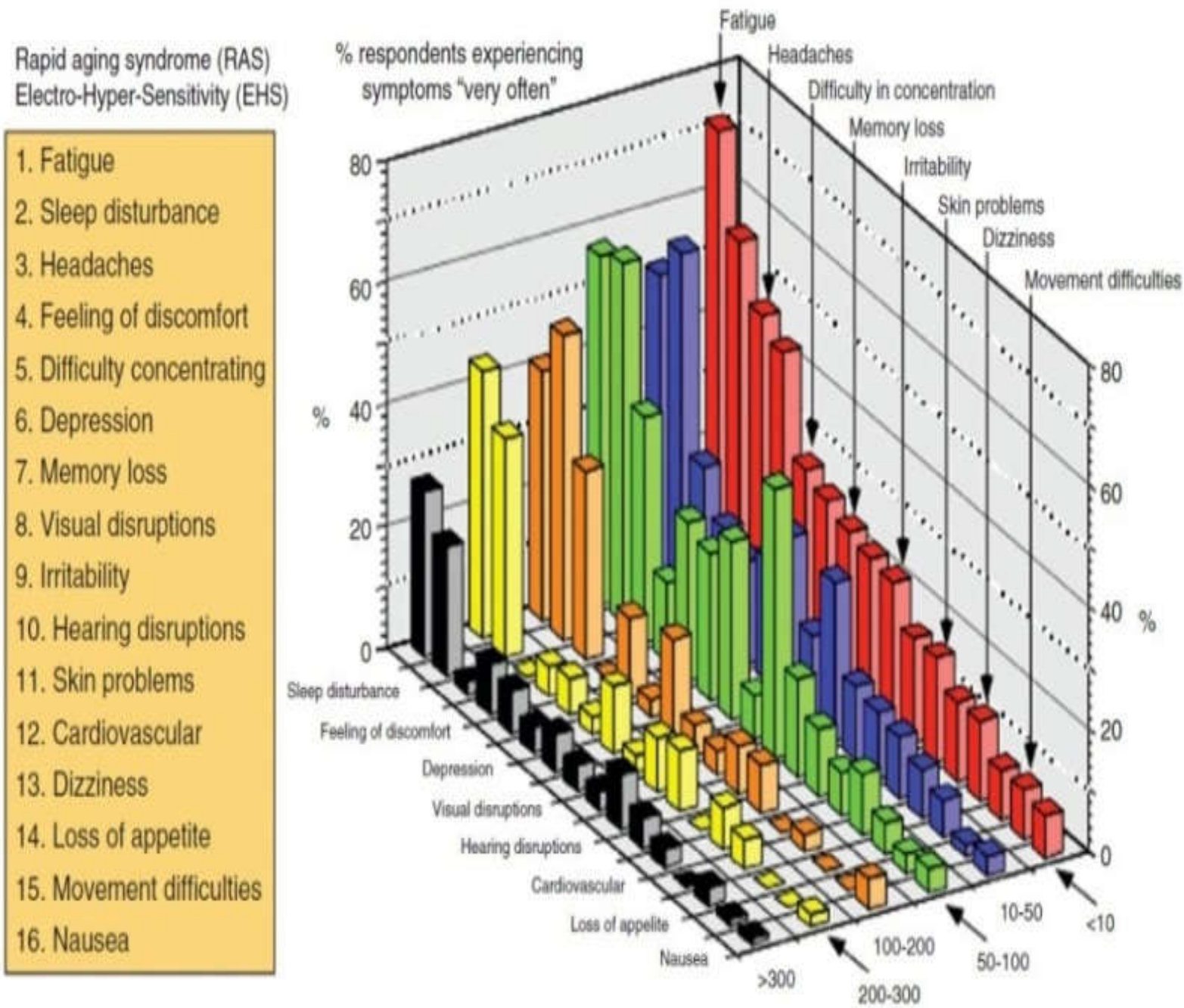

Residential distance of transmitter ( $\mathrm{m}$ )

Fig.1. Neurobehavioral symptoms near cell tower based on [14]

Table 1. Wide range of neuropsychiatric effects

\section{Radiofrequency Exposure Method Used in Identify Symptoms Suffered By \\ Population}

Living near cell phone base stations [14]
A survey study using a questionnaire was conducted on 530 participants. General questions pertained to age, sex, estimated distance from base station and the duration of living in the neighbourhood of base station. 


\begin{tabular}{|c|c|}
\hline $\begin{array}{c}\text { Living near cell phone base } \\
\text { station }[15]\end{array}$ & $\begin{array}{l}\text { A survey study using a questionnaire was conducted } \\
\text { on } 101 \text { participants. Questionnaire was from } \\
\text { which refers to address, sex, age, distance from base } \\
\text { stations and exposure time. The survey was assisted } \\
\text { by electric field measurement. }\end{array}$ \\
\hline $\begin{array}{l}\text { Living near mobile phone } \\
\text { base station [16] }\end{array}$ & $\begin{array}{l}\text { In identify the possible neurobehavioral deficit, a } \\
\text { survey study using a questionnaire was conducted on } \\
85 \text { participants with a control group with } 80 \\
\text { participants. The questionnaire contains on personal, } \\
\text { educational and medical history (general and } \\
\text { neurological examination) and neurobehavioral test } \\
\text { battery (involving visuomotor speed, problem } \\
\text { solving and memory) with addition of Eysenck } \\
\text { personality questionnaire. }\end{array}$ \\
\hline $\begin{array}{c}\text { Excessive mobile phone use } \\
\text { [17] }\end{array}$ & $\begin{array}{l}\text { A survey study using a self-administered } \\
\text { questionnaire was conducted on } 286 \text { participants. } \\
\text { The questionnaire was contained } 14 \text { items regarding } \\
\text { health condition and the frequency of mobile phone } \\
\text { used. }\end{array}$ \\
\hline $\begin{array}{l}\text { Use of mobile phone among } \\
\text { Adolescents [18] }\end{array}$ & $\begin{array}{l}\text { A questionnaire comprising of } 27 \text { questions with } 75 \\
\text { items in total was conducted on } 2000 \text { Swedish } \\
\text { adolescents aged } 15-19 \text { years and selected from the } \\
\text { population registry using a stratified sampling } \\
\text { scheme. The survey was assisted by blood sample } \\
\text { test. }\end{array}$ \\
\hline
\end{tabular}


Mobile phone use [19] A survey study using a questionnaire was conducted on 214 participants. A 14-items questionnaire investigating mobile phone use was consist of frequency, duration, quality and severity of symptoms such as headache, nausea and vomiting. The questionnaire also consists of current status of mobile phone use by participants.

High mobile phone use [20] A prospective cohort study was done by distributed questionnaire to 4156 participants consisted of young adults among 20-24 years old. The questionnaire demanded the mental health outcomes included sleep disorder and depression.

Living near mobile phone A survey study using a questionnaire was conducted base stations [21] on 500 participants in assesses the health conditions and subjective symptoms. The questionnaire contained occupational and environmental exposure to EMF, health conditions and subjective complaints. The survey was assisted by the electric field measurements.

Living near mobile phone base stations [22] A survey study using a structured questionnaire was conducted on 201 participants with objective of determining the possible health effects using 14 non-specific health symptoms. The questionnaire contained health related problems and public concern.

Each mobile phone network is given a set of frequencies, which use to receive and transmit information to each other mobile phone. Each mobile phone then divides each network location up into cells. Each network cell has a base station. When turn on mobile phone, it communicates and detecting with its closest base station and shares information about where 
the location of mobile phone are located. When dialing or taking a call from another mobile phone it another location, there are situation that identify who and where the person was talking from, the network operation will determining which microwave frequencies phones should be use so that there will be a communication between both party. Once there are establish connection, it easily to talk without words being delay even though there are quite a distances from each other.

When the person use mobile phone to call or receiving call or text message, the mobile phone user body absorbs amount of the radiation from frequency signal, and there might be a little health issues associated with this issues. The electromagnetic spectrum is classified into non-ionizing radiation and ionizing radiation. Non-ionizing radiation does not damage the genetic cell in body's molecules, and might or might not cause illness, but if the exposure to microwave radiation is sufficiently intense, then it can cause biological damage, such as cataracts and bums. On the other hand, Ionizing radiation is dangerous to our bodies and absorption in high doses can cause cancer and birth defects. Radio frequencies and microwave frequencies are classified as non-ionizing radiation and x-rays and gamma rays are examples of ionizing radiation.

There is a lot of debate about whether or not the type of radiation from the mobile phone, which comes from receiving call and sending text message from mobile phone possess danger to humans. Most of the researchers know the level of radiation decreases with distance but since the mobile phone is put very close to the head, many researchers are studying whether the rise in mobile phone usage and user is creating a rise in chronic health problem such as brain tumors. There have been a lot of studies done, but the results have been inconclusive.

\section{CAUSALITY}

Causality refers to the relationship between events where one set of events is a direct consequence of another set of the events. Causal inference is the process by which one can use data to make claims about causal relationships. To provide basis for intervention of research and to provide the understanding for research are two major purposes in epidemiological study in providing evidence. It is necessary to identify the real cause in 
observed association of study [15]. Since inferring causal relationships is one of the central tasks of science, it is a topic that has been heavily debated in in philosophy, statistic and the scientific disciplines. Causal relationship is one that has a establish process that by the causal role itself makes a dissimilarity. The scientific process of identify and managing of causal relationships can proceed using epidemiology employs difference-making in. how much the cause can affect the effect of one variable. The other approach which has a compatible role such as in identify the establish process, explaining how it influence the characteristic of the effect [16-17]. Hume argued that three empirical phenomenon were necessary for inferring causality: contiguity-the cause and effect must be contiguous in time and space, succession-the cause must be prior to the effect and constant conjunctions-there must be a constant union between the cause and effect.

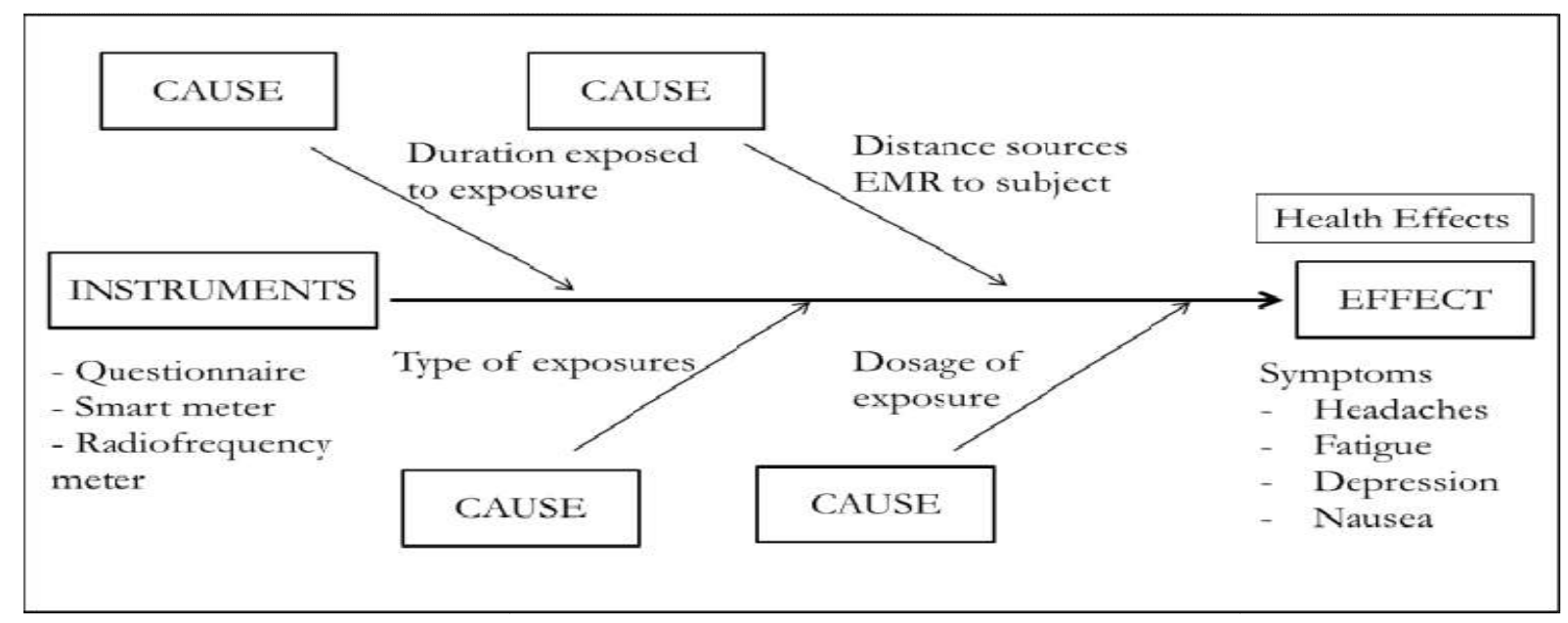

Fig.2. Cause and effect diagram in radiation health effects

A good process diagram is a diagram that gives better understanding and provides an essential supporting structure for statistical analysis by making the pathways, as detail as it could in a web of causation. Then, it can serves as a useful practice tool. It not only provides various key points for intervention, but also has the ability to show the evidence and proof in measure the inter-connection of divergent factors including unwanted and possibly unpredicted secondary effects. It is infrequent to find causal diagrams being used as the foundation for the statistical analysis of a approach although influence diagrams have been used unofficial to illuminate hypotheses on the certain pathways that may be utilize [18], as has been suggest in the circumstances of seek the evidence base for health impact assessment or strategic health 
assessment [19-20].

Causal diagrams are different from "mental maps" because they intend to explain connection in the reality world. The suitable formation for a certain approach is always driven by the process, so that the diagram is establish by knowledge of the definite and feasible pathways. For most people, this is an instinctive and quite uncomplicated task, and unofficial diagrams have been used in non-educational setting. A diagram can be operate as the core for a one study using a sole dataset, but is not restricted to this. As it conceptually maps out the research topic, it can have the framework of combination of the evidence from several different studies including combination of couple of datasets that conceal contrast parts of the causal web and rendition of quantitative as well as qualitative links. Thus, the diagram can be improved with current proof as it accumulates.

Determine by the degree of strength across different setting, the approach of a given model to contrast populations may necessitate its alteration. For instance, if the causal variable for each element link varies between populations and if its form is standardized, the origin of such standardized can be comprise in the causal diagram, generating a "hierarchical" framework.

It may be leave the impression that social relationships are less stable than biological ones, but this is not definitely correct: for example in the diagram showed in Fig. 3, the relationships of socioeconomic status with the distribution of age at the time of reproduction and with maternal smoking have been found to be highly stable [19].

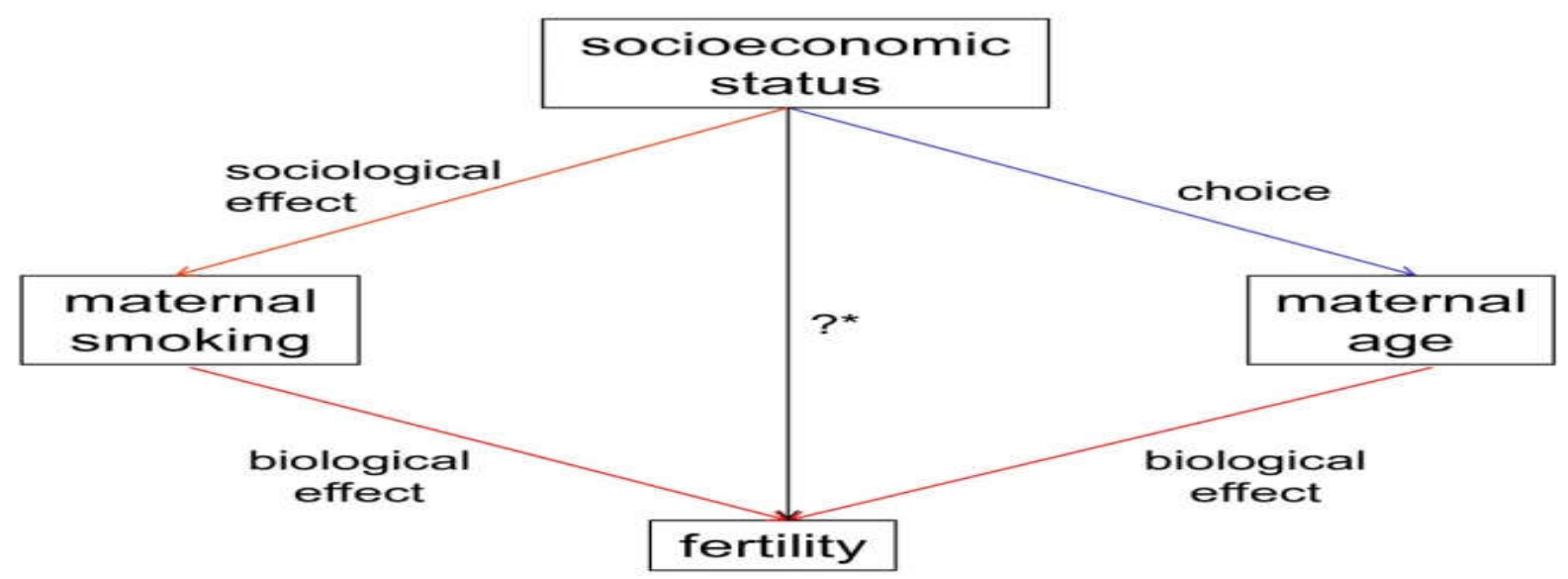

Fig.3. shows cause and effect diagram in radiation health effects 
3. CRITERIA FOR ASSESSING CAUSALITY IN EPIDEMIOLOGICAL STUDIES

Table 2. Definition of Hill's criteria [21]

\begin{tabular}{ll}
\hline \multicolumn{2}{c}{ Criteria } \\
\hline 1. Strength & The size of the risk as measure by appropriate tests \\
2. Consistency & $\begin{array}{l}\text { The association is consistent when results are replicated in studies } \\
\text { in different settings using different method }\end{array}$ \\
3. Specificity & When a single putative cause produces a specific effect \\
4. Temporal & Exposure always precedes the outcome
\end{tabular}

5. Dose response

An increasing level of exposure (in amount and/or time) increases the risk

6. Experimental The condition can be altered (prevented or ameliorated) by an evidence appropriate experimental regimen

7. Biologic The association agrees with currently accepted understanding of plausibility pathobiological processes

8. Coherence The association should be compatible with existing theory and knowledge

9. Analogy

A findings analogous associations between similar factors and similar diseases

The so-called criteria of causation came from Sir Austin Bradford Hill and Mervyn Susser work, criteria of causation were often applied despite the fact that they were meant neither as criteria nor as a checklist for contributing to a hazard the potential of disease causation. There were five common criteria that should be considered in making that judgment [22]; (1) strength of association, (2) biological credibility, (3) consistency, (4) time sequence, and (5) dose-response relationship. Each of these five criteria provides strong support for causality because of the combination of all five provides evidence for causality [23]. However, according to Hill criteria, there were nine criteria can be used for assessing causality. The strength of association can be defined by the stronger the association between a risk factor and 
outcome, the more likely the relationship is to be causal. For biological credibility, change in disease rates should follow from corresponding changes in exposure. Meanwhile, for consistency of causality, the study must have the same findings but must be observed in different populations, in different study designs and different times and for time sequence and dose-response relationship the exposure must precede outcome [24]. Dose-response relationship can be assumed when the biological effects have a positive correlation with the intensity of the causal stressor. This is not necessarily true of EMR effects because it has been shown that there are "window effects", where the intensities have larger biological effects but with either lower or higher intensities [25-26]. Thus, these data do fit well to the assumed dose-response relationship commonly found in most causal roles.

\section{LEVELS OF EVIDENCE AND PUBLIC HEALTH INTERVENTIONS}

In estimating the effect of exposure on disease, it is important in adjusting for confounders in common practice. Decide whether potential confounders based on condition on adjusted estimate to crude estimate were real confounders.

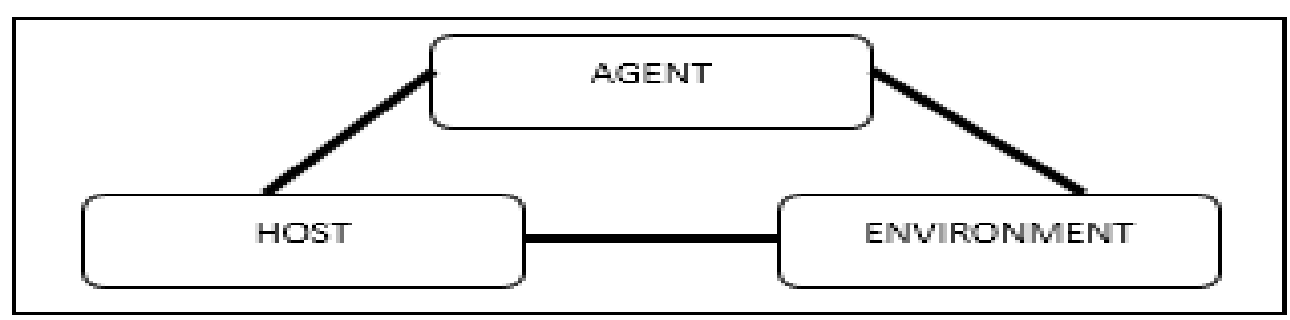

Fig.4. Epidemiological triad

This epidemiological triad comprises a susceptible host (the person at risk for the disease), a disease agent (the proximate cause) and an environmental context for the interaction between host and agent. However, this epidemiological triad model was widely used in identify cause and effect for communicable disease [27]. 


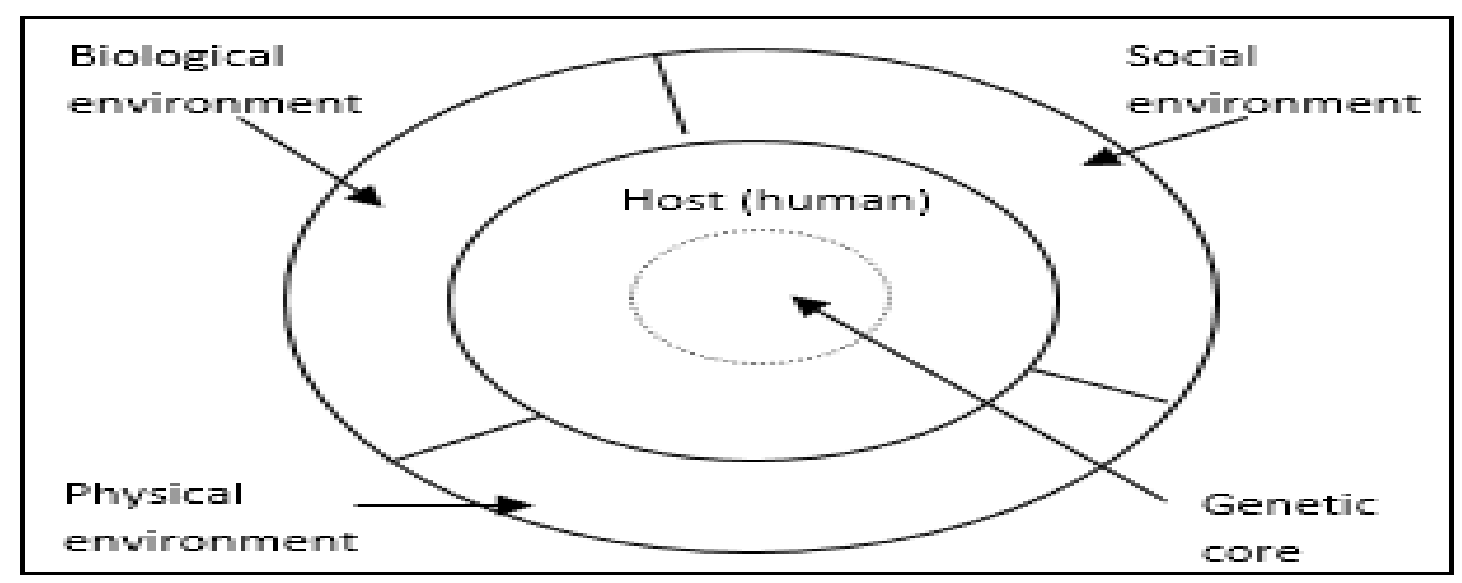

Fig.5. The wheel of causation

The wheel of causation by Mausner and Kramer de-emphasizes the agent as the sole cause of disease, while emphasizing the interplay of physical, biological and social environments (Fig. 5). It also brings genetics into the mix.

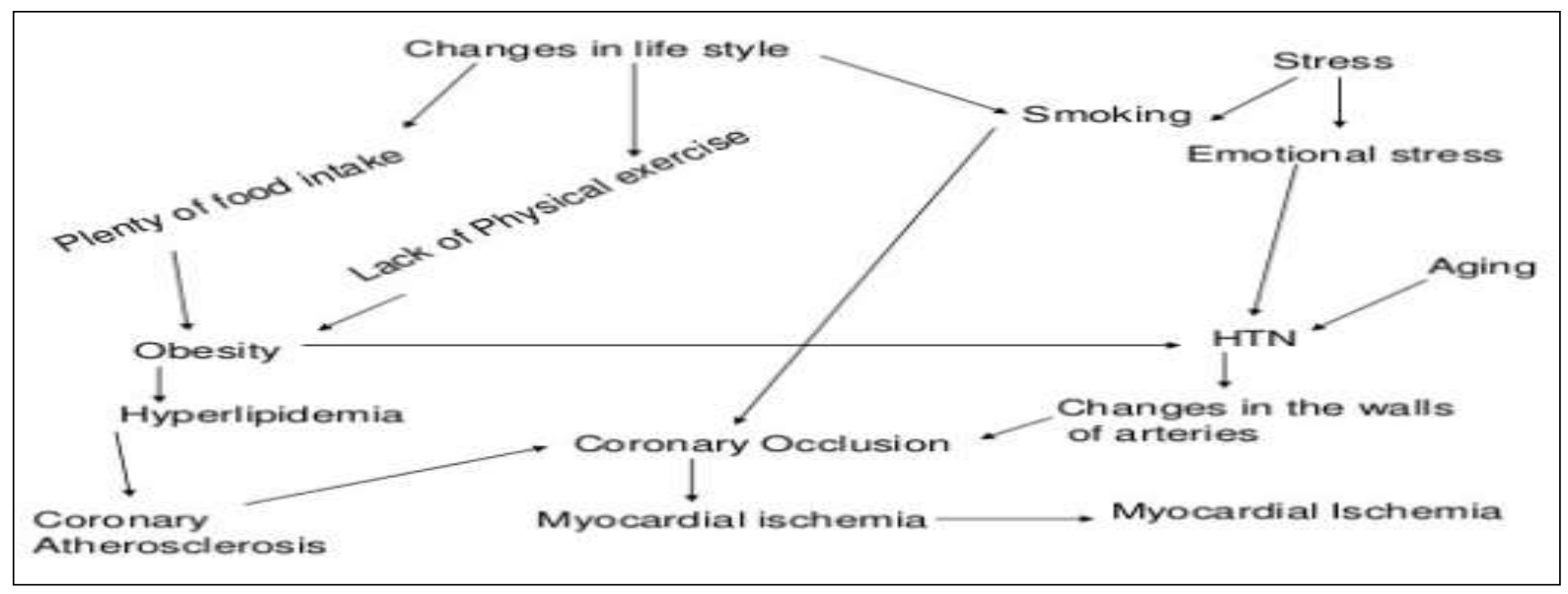

Fig.6. The web of causation

Same as the wheel of causation, the web of causation shows an interrelationship of multiple factors that contribute to the occurrence of a disease that cross various pathways. Adherence to a cyclical and long process based on reality, these causal webs can be quite complex and convoluted. While the web of causation was design to elevate and enhance understanding of non-communicable chronic disease, this web of causation also has importance to describe type of injury and communicable disease [27].

Centre Disease Control (CDC) has comes out with four steps in developing and elaborate public health information consist of public health surveillance, risk group identification, risk factor identification and program development, implementation and justification [28]. 
1. Public health surveillance-the continuous, systematic collection, analysis and interpretation of health-related data needed for the planning, implementation and evaluation of public health practice.

2. Risk group identification-involves considering the possible results of someone being exposed to risk of disease or injury and the places, times, and other situations that are related with situated risks

3. Risk factor identification-scientific observation of possibility causative risk factors for disease, injury or mortality as proposed by the high risk population

4. Program development, implementation and justification-design, implementation and evaluation of preventive interventions based on degree of understanding of the population at risk and the risk factors for the outcome of interest.

The early two steps subside under the area of descriptive epidemiology. Step three and four subside under analytic epidemiology area with its ability to explore both cause and effect relationships and interventions based on this etiologic understanding. These four steps take us from acknowledgement of a public health problem through its resolution (Fig. 7).

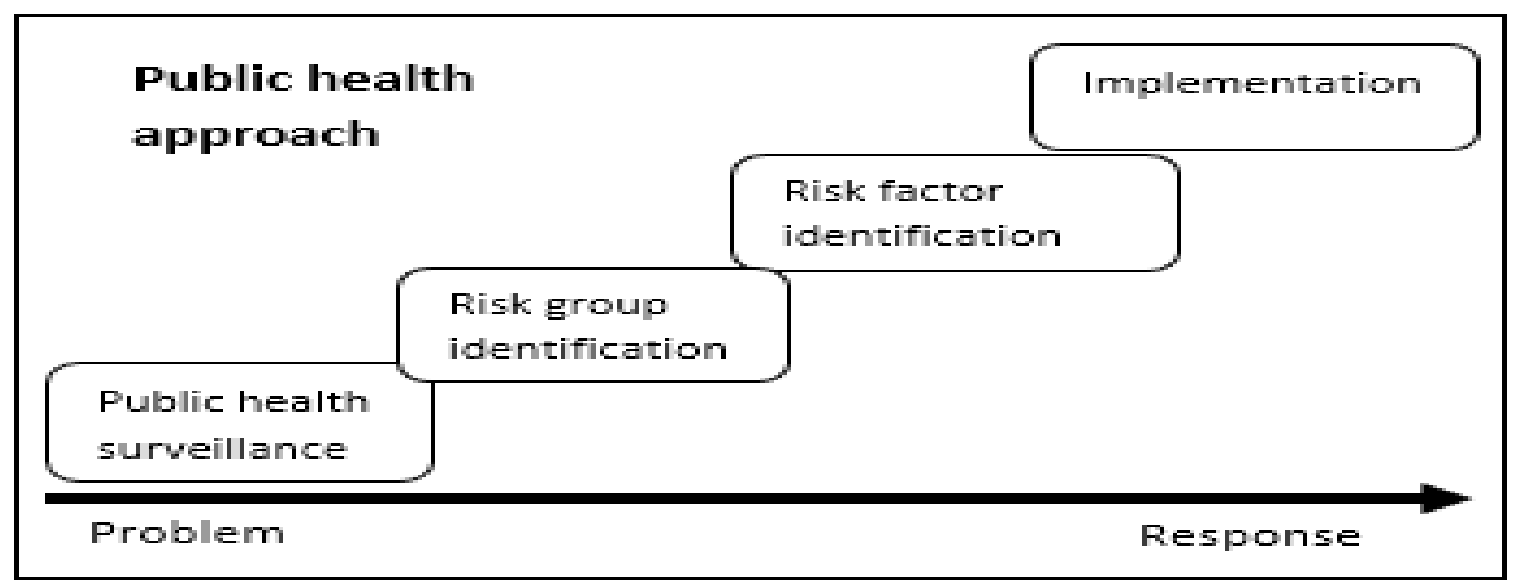

Fig.7. The public health approach to problem solving

The level of evidence is importance for the assessment of causality for public health interventions [29]. Levels of evidence have also been applied to other areas such as in decision maker in health care group including economic analysis, diagnosis and prognosis. Causal inference in epidemiology was perceived better as tools in the assessment of an effect rather than as an assist process for deciding whether an effect was there or not [30]. It is 
requirement to take the entire body of evidence that is convenient to try to appear at an equitable cessation about the relationship when the all-inclusive evidence from epidemiology and other sources interventions became coherent. Some studies have stated that unambiguous and coherent observational designs can create excellent and advantageous ruling in the epidemiological study, although more empirical evidence is necessitate since resolution about public health interventions should be construct based on an extensive assessment of the flaw, gaps and dominance in the evidence.

Based on [31] decisions about practice demand a measure of several element to get the justifiable findings such as the distinguish magnitude and significance of the problem, the practicable of its implementation, the possible harms of the intervention, and the public desire for act. Different interest groups may concur and assist for participate for endorsement.

\section{CONCLUSION}

The assessment of process and confirmation should be complement with the stage of progress of the intervention. The evaluation should also be intended to discover and identify all the essential effects of the intervention. With the causality of cause and outcomes in an epidemiological study the confirmation can be justify. Another factor causing that exposure to the people located at the same distance from the base station may be different as EMR from base station is absorbed by the building materials [32-33]. Thus, according to the general opinion of experts, human EMR exposures should not be based solely on the inhabitants' distance from the base station; instead, true EMR value should be determined.

Those which have been performed were limited to the questionnaire survey, they were often faced with the subjectivism-related error and it was not easy to determine the causes of the reported complaints. In epidemiological studies, there are always based on two basic assumptions which were human disease does not occur at random and the disease and its cause as well as preventive factors can be identified by a thorough investigation of population. Hence, identification of causal relationship between a disease and suspected risk factors form part of epidemiological research. 


\section{ACKNOWLEDGEMENTS}

The authors would like to acknowledge the Ministry of Education for grant FRGS/1/2015/SG02/UNISZA/02/1.

\section{REFERENCES}

[1] Brenner D J, Doll R, Goodhead D T, Hall E J, Land C E, Little J B, Lubin J H, Preston D L, Preston R J, Puskin J S, Ron E. Cancer risks attributable to low doses of ionizing radiation: Assessing what we really know. Proceedings of the National Academy of Sciences, 2003, 100(24):13761-13766

[2] Arslanoglu A, Bilgin S, Kubali Z, Ceyhan M N, İlhan M N, Maral I. Doctors' and intern doctors' knowledge about patients' ionizing radiation exposure doses during common radiological examinations. Diagnostic and Interventional Radiology, 2007, 13(2):53-55

[3] Felix O K, Gabriel A U, Emmanuel A C. Investigation and analysis on electromagnetic radiation from cellular base station transmitters and the implications to human body. Journal of Environment and Ecology, 2014, 5(1):46-60

[4] Berg-Beckhoff G, Blettner M, Kowall B, Breckenkamp J, Schlehofer B, Schmiedel S, Bornkessel C, Reis U, Potthoff P, Schüz J. Mobile phone base stations and adverse health effects: Phase 2 of a cross-sectional study with measured radio frequency electromagnetic fields. Occupational and Environmental Medicine, 2009, 66(2):124-130

[5] Bortkiewicz A, Gadzicka E, Szyjkowska A, Politański P, Mamrot P, Szymczak W, Zmyślony M. Subjective complaints of people living near mobile phone base stations in Poland. International Journal of Occupational Medicine and Environmental Health, 2012, 25(1):31-40

[6] C. Parslow R, J. Hepworth S, A. McKinney P. Recall of past use of mobile phone handsets. Radiation Protection Dosimetry, 2003, 106(3):233-240

[7] Auvinen A, Toivo T, Tokola K. Epidemiological risk assessment of mobile phones and cancer: Where can we improve? European Journal of Cancer Prevention, 2006, 15(6):516-523 [8] Hardell L, Sage C. Biological effects from electromagnetic field exposure and public exposure standards. Biomedicine and Pharmacotherapy, 2008, 62(2):104-109 
[9] Neubauer G, Feychting M, Hamnerius Y, Kheifets L, Kuster N, Ruiz I, Schüz J, Überbacher R, Wiart J, Röösli M. Feasibility of future epidemiological studies on possible health effects of mobile phone base stations. Bioelectromagnetics, 2007, 28(3):224-230

[10] Blettner M, Schlehofer B, Breckenkamp J, Kowall B, Schmiedel S, Reis U, Potthoff P, Schuez J, Berg-Beckhoff G. Mobile phone base stations and adverse health effects: phase 1 of a population-based, cross-sectional study in Germany. Occupational and Environmental Medicine, 2009, 66(2):118-123

[11] Berg-Beckhoff G, Blettner M, Kowall B, Breckenkamp J, Schlehofer B, Schmiedel S, Bornkessel C, Reis U, Potthoff P, Schüz J. Mobile phone base stations and adverse health effects: Phase 2 of a cross-sectional study with measured radio frequency electromagnetic fields. Occupational and Environmental Medicine, 2009, 66(2):124-130

[12] Australian Radiation Protection and Nuclear Safety Agency (ARPANSA). Analysis of EMR health complaints register data 2015-2016. https://www.arpansa.gov.au/sites/g/files/net3086/f/legacy/pubs/emr/analysis15-16.pdf

[13] Havas M, Marrongelle J, Pollner B, Kelley E, Rees C R, Tully L. Provocation study using heart rate variability shows microwave radiation from $2.4 \mathrm{GHz}$ cordless phone affects autonomic nervous system. European Journal of Oncology Library, 2010, 5:273-300

[14] Santini R, Santini P, Le Ruz P, Danze J M, Seigne M. Survey study of people living in the vicinity of cellular phone base stations. Electromagnetic Biology and Medicine, 2003, 22(1):41-49

[15] Joffe M, Gambhir M, Chadeau-Hyam M, Vineis P. Causal diagrams in systems epidemiology. Emerging Themes in Epidemiology, 2012, 9(1):1-18

[16] Joffe, M. Causality and evidence discovery in epidemiology. In D. Dieks, W. J. Gonzalez, S. Hartmann, T. Uebel, M. Weber (Eds.), Explanation, prediction, and confirmation. Berlin: Springer Verlag, 2011, pp. 153-166

[17] Joffe M. The gap between evidence discovery and actual causal relationships. Preventive Medicine, 2011, 53(4):246-249

[18] Joffe M, Mindell J. Complex causal process diagrams for analyzing the health impacts of policy interventions. American Journal of Public Health, 2006, 96(3):473-479 
[19] Joffe M. The need for strategic health assessment. European Journal of Public Health, 2008, 18(5):439-440

[20] Joffe M. The role of strategic health impact assessment in sustainable development. International Journal of Green Economics, 2010, 4(1):1-6

[21] Gordis L. Epidemiology. Pennsylvania: Elsevier, 2013

[22] Hennekens C. H., Buring J. E., Mayre S. L. Epidemiology in medicine. Pennsylvania: Lippincott Williams and Wilkins, 1987

[23] Pall M L. Microwave frequency electromagnetic fields (EMFs) produce widespread neuropsychiatric effects including depression. Journal of Chemical Neuroanatomy, 2016, 75:43-51

[24] Rothman K. J. Modern epidemiology. Pennsylvania: Lippincott Williams and Wilkins, 1998

[25] Panagopoulos D J, Johansson O, Carlo GL. Evaluation of specific absorption rate as a dosimetric quantity for electromagnetic fields bioeffects. Plos One, 2013, 8(6):1-9

[26] Ian R. H. R. Descriptive epidemiology for public health professionals part 2. Sudanese Journal of Public Health, 2005, 4(3):354-359

[27] Belyaev I. Chapter 5: Biophysical mechanisms for nonthermal microwave effects. In M.

S. Markov (Eds.), Electromagnetic fields in biology and medicine. New York: CRC Press, 2015, pp. 49-67

[28] Centre Control Disease (CDC). Principles of epidemiology in public health practice: An introduction to applied epidemiology and biostatistics. Georgia: U.S. Department of Health and Human Services, 2012

[29] Rychetnik L, Frommer M, Hawe P, Shiell A. Criteria for evaluating evidence on public health interventions. Journal of Epidemiology and Community Health, 2002, 56(2):119-127

[30] Rothman K J, Greenland S. Causation and causal inference in epidemiology. American Journal of Public Health, 2005, 95(S1):S144-150

[31] Sauerborn R, Nitayarumphong S, Gerhardus A. Strategies to enhance the use of health systems research for health sector reform. Tropical Medicine and International Health, 1999, 4(12):827-835 
[32] Parsons J. D. The mobile phone propagation channel. New York: Wiley and Sons, 1992

[33] Mann S M, Cooper T G, Allen S G, Blackwell R P, Lowe A J. Exposure to radio waves near mobile phone base stations. NRPB-R321 report, Oxfordshire: National Radiological Protection Board, 2000

\section{How to cite this article:}

Yussof FM, Umar R, Juahir H, Hassan A.The criteria for evaluating method and evidence on radiation health effects in epidemiological study: a review. J. Fundam. Appl. Sci., 2017, 9(2S),

317-334. 